\title{
In vitro studies on viability and proliferation of Enteromyxum scophthalmi (Myxozoa), an enteric parasite of cultured turbot Scophthalmus maximus
}

\author{
María J. Redondo, Oswaldo Palenzuela*, Pilar Alvarez-Pellitero \\ Consejo Superior de Investigaciones Científicas, Instituto de Acuicultura Torre la Sal, 12595 Ribera de Cabanes, \\ Castellón, Spain
}

\begin{abstract}
In vitro cultivation of the myxozoan Enteromyxum scophthalmi was attempted using different culture media and conditions. The progress of the cultures was monitored using dye-exclusion viability counts, tetrazolium-based cell-proliferation assays, measuring the incorporation of BrdU during DNA synthesis, and by morphological studies using light and electron microscopes. In preliminary experiments, the persistence of viable stages for a few days was ascertained in both medium 199 (M199) and in seawater. An apparent initial proliferation was noticed in the culture media, with many young stages observed by Day 7 post-inoculation (p.i.). In contrast, fast degeneration occurred in seawater, with but a few living stages persisting to Day 1 p.i and none to Day 5 p.i. Both tetrazolium-based cell-proliferation assays and dye-exclusion viability counts demonstrated a progressive degeneration of the cultures. Although M199 medium and neutral pH with the addition of sera appeared to provide the most favourable conditions during the first few hours, all cultures degenerated with time and no parasite proliferation or maintenance could be achieved in the long term in any of the conditions assayed, including attempts of co-cultivation with a turbot cell line. The ultrastructure of stages cultured for $15 \mathrm{~d}$ demonstrated complete degeneration of organelles and mitochondria, although the plasma membrane remained intact in many stages. Unknown factors related to the metabolism or the life cycle of this myxozoan are probably responsible for the inability to culture the parasite, which seems to be strictly dependent on the target host tissues for survival.
\end{abstract}

KEY WORDS: Myxozoa $\cdot$ In vitro cultivation · Parasites $\cdot$ Life cycle

\section{INTRODUCTION}

Most studies on different aspects concerning parasites depend on a homogeneous and reliable source of parasitic test material. This has traditionally been a major limitation for studies with myxozoans, as trials on transmission from mature myxospores to uninfected fishes are ineffective. For a number of freshwater species, experimental infections can be achieved through invertebrate hosts in which the stage infective for fishes (the actinosporean) is produced, or by exposure of healthy fishes to known enzootic waters (reviewed by Kent et al. 2001). A few myxosporidioses can also be transmitted in laboratory conditions by intracoelomic injections of extrasporogonic stages such as the proliferative kidney dis- ease myxozoan (Hedrick et al. 1993), Ceratomyxa shasta (Ibarra et al. 1991) or Kudoa thyrsites (Moran et al. 1999). Although an alternating fish-invertebrate life cycle is assumed for most, if not all, species in this group (Kent et al. 2001), recent evidence has demonstrated spontaneous fish-to-fish transmission in species of the marine genus Enteromyxum (Diamant 1997, Redondo et al. 2002). Although there are a few reports on marine actinosporeans (Ikeda 1912, Hallet et al. 1998, Køie 2000), none of their putative myxosporean counterparts has been identified to date. The life cycle of marine myxozoans still remains to be clarified, and research in this field is largely limited by the natural sources of parasite material.

Because of these limitations, very little information is available in the literature on attempts of myxozoan cul- 
tivation. Wolf \& Markiw (1976) inoculated Myxobolus cerebralis-infected rainbow trout cartilage in Eagle's minimum essential medium (MEM), obtaining mature spores in 6 of 7 trials. In vitro sporulation of Ceratomуха spp., in the absence of host material, has also been reported by Palenzuela et al. (1994) and Yokoyama \& Yutaka (1999). Siau (1977) carried out short-term studies using cultures of Myxobolus exiguus sporoplasms, after the myxospores of this species had been mechanically broken and the sporoplasms inoculated into cultures of trout cells. The remaining information is limited to some experiments on the in vitro survival of $M$. cerebralis and Thelohanellus kitauei myxospores exposed to different saline solutions and various physical and chemical factors (Hoffman \& Hoffman 1972, Rhee et al. 1990, Rhee 1994). Similar studies have also been carried out with actinospores, which have been maintained in vitro for up to $4 \mathrm{wk}$ while longevity, phototaxis and chemotaxis were examined (Yokoyama et al. 1995).

Different procedures are available for the evaluation of cellular activity and/or proliferation in vitro. The aim of such assays is to provide simple, reproducible methods for assessing the number of cells present in a given culture. Metabolic assays using tetrazolium salts such as MTT, XTT or WST-1 are intended to determine the whole metabolic activity as an indirect measure of the number of viable cells present. They are based on the reduction of these tetrazolium salts by cellular enzymes, generally involving NADH and NADPH. Cell proliferation can also be assessed by measuring the incorporation of a labelled or modified nucleotide, such as bromodeoxyuridine (BRDU) by an enzyme immunoassay, as an indicator of DNA synthesis in proliferating cells.

Enteromyxum scophthalmi Palenzuela, Redondo \& Alvarez-Pellitero, 2002 is an enteric, histozoic myxozoan parasite that causes emaciative disease in farmed turbot Scophthalmus maximus. The pathogen invades the intestinal tract of the fish, causing acute enteritis and death (Branson et al. 1999, Redondo et al. 2002). Mortality can reach $100 \%$ of affected stocks. The purpose of the present study was the development of in vitro cultivation methods for E. scophthalmi as a source of material for subsequent studies. Parasite cultivation, alone or in co-culture with a cell line from turbot, was attempted. The influence of culture conditions, media and supplements was tested and estimated by periodic viability counts, tetrazolium-based cell-proliferation assays and/or measurements of incorporation of BRDU.

\section{MATERIALS AND METHODS}

Parasite material. Infected and uninfected Scophthalmus maximus (weight ranging from 63 to $772 \mathrm{~g}$ ) were obtained from turbot farms in NW Spain. Infection was maintained at the Instituto de Acuicultura Torre la Sal facilities by cohabitation of infected and uninfected fish (Redondo et al. 2002). Fish were killed by anaesthetising with oil of cloves, followed by severing of the spine and necropsy. The liquid present in the intestinal lumen was collected with a syringe and deposited in 15 ml centrifuge tubes containing Hanks' balanced salt solution (HBSS) supplemented with an antibiotic/antimycotic mixture $\left(1 \times \mathrm{PSA}=100 \mathrm{U} \mathrm{ml}^{-1}\right.$ penicillin, $100 \mu \mathrm{g}$ $\mathrm{ml}^{-1}$ streptomycin, and $0.25 \mathrm{\mu g} \mathrm{ml}^{-1}$ amphotericin B). A drop of the intestinal liquid was observed as a fresh smear under the microscope at $300 \times$, and the presence of parasitic developmental stages was evaluated and registered, ranking the infection intensity from $1+$ to $6+$. Only samples with infection intensity $3+$ or higher were processed further. These were centrifuged for $10 \mathrm{~min}$ at $365 \times g$, and the pellet was washed twice in fresh HBSS containing $2 \times$ PSA. Stages in the pellet were counted and their viability was estimated using dye-exclusion methods. Sterile material and aseptic techniques were used throughout.

Culture media. M199 (Medium 199), DME/F12 (Dulbecco's modified Eagles's medium/Ham's nutrient mixture F-12), and HMEM (Eagle's minimum essential medium with Hanks' salts) were the culture media tested with the parasite alone, and L-15 (Leibovitz's L15 medium) was used in co-cultures with cell lines. All media were supplemented with $10 \%$ heat-inactivated foetal bovine serum (FBS) and $1 \times$ PSA unless indicated otherwise. Osmolarity was adjusted to $350 \mathrm{mOsm} \mathrm{kg}^{-1}$ by the addition of $\mathrm{NaCl}$. Media $\mathrm{pH}$ were adjusted to 6.5, 7.2 or 8 to 8.5 with $10 \mathrm{mM}$ bis-Tris, $20 \mathrm{mM}$ HEPES and $50 \mathrm{mM}$ tricine, respectively.

Cell line. Monolayers of TF (turbot fin) cell line (developed by Dr B. Hill, MAFF Fish Disease Laboratory, Weymouth, UK) were grown at $20^{\circ} \mathrm{C}$ in L- 15 medium containing $10 \%$ FBS, 20 mM HEPES and $3.5 \mathrm{~g} \mathrm{l}^{-1} \mathrm{NaCl}$. Cells were routinely split and subcultured 1 to 3 using normal trypsin/EDTA solution $(0.25 \%$ trypsin, $1 \mathrm{mM}$ EDTA). Cells were seeded in 24 -well plates $\left(10^{5}\right.$ cells per well) and were allowed to grow and reach confluence for 2 to $3 d$, prior to experimental use.

Experimental design. Assays and cultures were set up as follows:

Preliminary assays: In a first series of experiments, the viability of parasite stages in the intestinal liquid, in HBBS containing $1 \times$ PSA and in seawater was compared. Samples were taken after $30 \mathrm{~min}, 24$ and $96 \mathrm{~h}$ for each experimental condition, and the number of viable stages was counted with a Neubauer haemocytometer, using different viability dye-exclusion methods (eosin, eosin-nigrosin and trypan blue). In a subsequent experiment, parasite stages were transferred directly from the intestinal liquid to M199 or to seawater. Observations of 
the parasite morphology and viability were carried out at $1,2,5,7,9,12$ and $15 \mathrm{~d}$ post-inoculation (p.i.), using an inverted microscope (IM) and studying samples of the cultures as fresh smears with the light microscope (LM). In addition, transmission electron microscope (TEM) studies were conducted. Both the inoculum and the material collected on Day 15 p.i. were centrifuged for $10 \mathrm{~min}$ at $365 \times g$, and the pellets were fixed in $2.5 \%(\mathrm{v} / \mathrm{v})$ glutaraldehyde in $0.1 \mathrm{M}$ cacodylate buffer (pH 7.2). Samples were washed several times with the same buffer, postfixed in $1 \%(\mathrm{w} / \mathrm{v})$ cacodylic OsO4, dehydrated through a graded ethanol series, and embedded in Spurr's resin (Spurr 1969). Ultrathin sections were double-stained with uranyl acetate and lead citrate.

Culture of parasite alone: Tissue-culture multiwell plates were inoculated with the number of viable stages required for each experiment. The following conditions were tested: temperature $=15$ and $20^{\circ} \mathrm{C}_{i}$ culture media $=$ M199, DME/F12, HMEM and conditioned medium (a 1:2 mixture of M199 and the supernatant of TF monolayers); media $\mathrm{pH}=6.5,7.2,8,8.5$, in M199; serum addition = heat-inactivated FBS $(5$ or $10 \%)$, turbot serum (TS) (5 or $10 \%)$ or both sera (5\% FBS plus 5\% TS) in M199.

Co-culture of parasite with TF cells: Attempts were made to co-culture the parasite with host cells. For these experiments, TF cells were seeded in 24-well plates in L-15 medium. Before confluence was reached, parasites were added at concentrations ranging from 50000 to 350000 stages well ${ }^{-1}$. Control wells contained TF monolayers without parasites. Stages in the supernatant were harvested at fixed time intervals, and viability counts were carried out. In order to obtain additional information on the relationships of the parasite stages with turbot cells, in some experiments Thermanox coverslips (Nunc) were placed at the bottom of the wells. They were collected at 1, 2, 3, 4 and $6 \mathrm{~h}$ p.i., fixed with methanol, stained with toluidine blue, and mounted to be studied under the LM.

Monitoring cultures. Parasite growth was evaluated at different times p.i. using at least 1 of the following methods:

Direct counting of viable stages: This was carried out in a Neubauer hemocytometer using the eosin dyeexclusion method.

Cell proliferation with colorimetric assays: Cell proliferation and viability kits based on XTT or WST-1 reagents (Roche Diagnostics) were used. Both microplate assays are based on the enzymatic cleavage of tetrazolium salts. In viable cells, the reagents are metabolically reduced to coloured end-products that can be quantified with a scanning multiwell spectrophotometer. The assays were carried out with parasites seeded in 96-well plates at variable concentrations (3125 to 400000 viable parasites well $^{-1}$ ), and were repeated after fixed time intervals in culture. Both XTT and WST-1 reagents were used as directed by the provider of the kits.

Cell proliferation determined by ELISA BRDU: A commercial ELISA immunoassay for the measurement of cell proliferation through the quantification of BRDU incorporated during DNA synthesis was used (Roche Diagnostics). The procedure was applied following the manufacturer's protocol for non-adherent cells, with viable parasites seeded in 96-well plates as described above.

In addition, all the cultures were periodically observed using the IM. Samples were also taken for LM observation and microphotography when viability counts were carried out.

Statistics. The results of the cell proliferation assays and the viability counts are presented as mean values (3 replicate wells \pm SEM). The influence of different conditions was examined for significance by 1 -way ANOVA, followed by a Student-Newman-Keuls test when more than 2 variables were investigated, or with a Student's $t$-test when only 2 conditions were compared. Differences were considered statistically significant at $\mathrm{p}<0.05$.

\section{RESULTS}

\section{Preliminary assays}

In the first experiment, it was observed that parasite stages remained viable after $30 \mathrm{~min}$, either in the intestinal liquid, in HBSS with PSA, or in seawater. The basic parasite handling routines, including centrifugation and washings with HBSS, did not affect the stages' viability. The 3 stains tested (eosin, eosin-nigrosin and trypan blue) gave similar results for dye-exclusion viability counts, so eosin was chosen as the least toxic stain. After $24 \mathrm{~h}$, no relevant differences were observed among the 3 conditions. Most stages included eosin, although some stages remained viable and even showed amoeboid movement. In the last observation at $96 \mathrm{~h}$, no viable stages were found. In subsequent experiments, the parasites were processed immediately after they were obtained.

During the morphological LM study of the parasites present in the fresh intestinal liquid used to obtain the inoculum (Fig. 1), we observed a predominance of amoeboid stages in the size range 15 to $18 \mu \mathrm{m}$ with a primary $(\mathrm{P})$ cell harbouring several inner secondary $(\mathrm{S})$ cells, although some smaller (8 to $10 \mu \mathrm{m}$ ) and larger (19 to $25 \mu \mathrm{m})$ stages were also present. Some parasites were encompassed by a thin layer of host cells or displayed wide empty, vacuolar spaces, probably corresponding to released inner cells. 

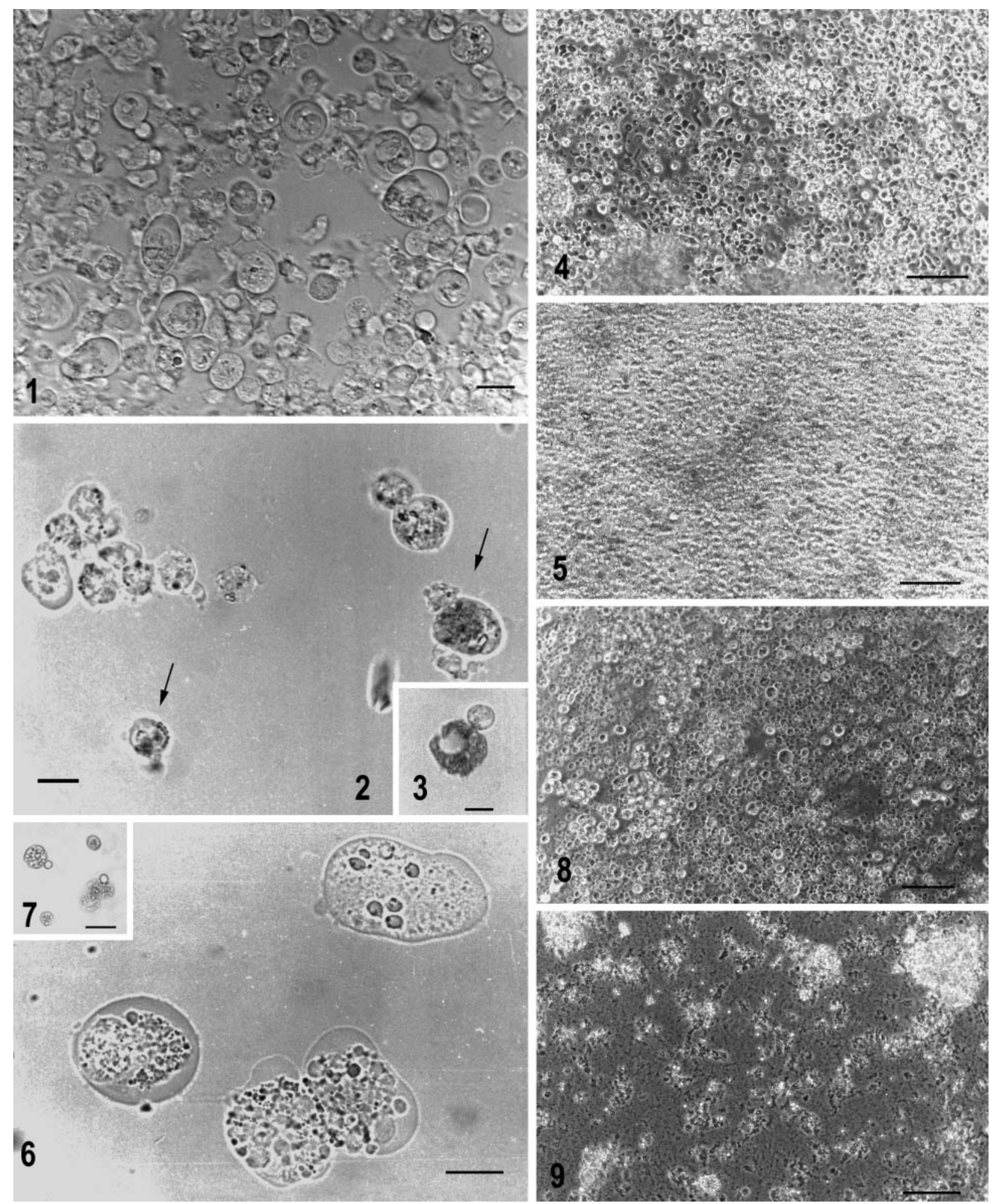

Figs. 1 to 9. Enteromyxum scophthalmi. Development of cultures. Fig. 1. Freshly obtained stages in intestinal liquid. Fig. 2. Stages after $24 \mathrm{~h}$ in medium 199 (M199); note that some primary cells have taken up the eosin dye (arrows). Fig. 3. Stage stained with eosin after $24 \mathrm{~h}$ in seawater. Figs. 4 \& 5. Cultures in inverted microscope $48 \mathrm{~h}$ after plating; apparently viable stages are abundant in M199 medium (Fig. 4) in contrast with amorphous material in seawater (Fig. 5). Fig. 6. Viable stage amoeboid after 48 h in M199. Fig. 7. Non-viable stages after $48 \mathrm{~h}$ in seawater. Figs. 8 \& 9. Images under inverted microscope $9 \mathrm{~d}$ after plating; some stages still conserved their integrity in M199 (Fig. 8), but only residual material could be found in seawater (Fig. 9). Scale bars = $10 \mu \mathrm{m}$ (Figs. 1, 2, 3,6 \& 7); $55 \mu \mathrm{m}$ (Figs. 4,5,8 \& 9) 
On Day 1 p.i. in M199, there were no significant alterations in the morphology of parasite stages and only some P cells were non-viable (Fig. 2). In contrast, after the same time in seawater, few live stages were observed (Fig. 3). The differences between both conditions were more evident in subsequent observations of the cultures, as only degraded material was observed in seawater, whereas abundant parasite stages, with apparently normal morphology, prevailed in M199 after $48 \mathrm{~h}$ (Figs. 4 \& 5). LM observations of the material on Day 5 p.i. confirmed the presence of abundant parasites in M199 (Fig. 6), with a predominance of large amoeboid stages (20 to $25 \mu \mathrm{m}$ ). At this time, eosin penetrating the P cell was commonly observed, whereas S cells ( 7 to $11 \mu \mathrm{m}$ ) remained viable and were sometimes being released from the degraded P cells. No living stages could be found in seawater at that time.

On Days 7 and 9 p.i., few amoeboid stages were found in M199. Most viable stages ranged from 12 to $15 \mu \mathrm{m}$, whereas a number of small stages (5 to $7 \mu \mathrm{m}$ ), which were usually non-viable, were also detected (Fig. 7). The IM images on Day 9 p.i. clearly illustrate the differences among M199 and seawater cultures, as only residual material could be observed in the latter (Figs. 8 \& 9). In subsequent observations, a progressive degeneration of the cultures was noticed, even in M199. On Day 12 p.i., some living stages were still detected in this medium, together with abundant residual material. On Day 15 p.i. (the last observation), all stages were non-viable.

Study of the ultrastructure of the parasites revealed their degeneration in culture. In fresh stages present in the inoculum (Figs. 10 to 13), S cells were densely packed with ribosomes and showed abundant mitochondria in different developmental phases (Figs. 11 to 13). $P$ cells also displayed vacuoles, lipid inclusions and carbohydrate granules. Some stages were found together with host-cell remnants, their membranes closely joined by gap junctions (Fig. 11). The membranes of isolated parasites occasionally showed remnants of this junction (Fig. 12). In parasites collected after $15 \mathrm{~d}$ in culture (Figs. 14 to 16), the cytoplasm was completely degraded and only membrane debris, residual mitochondria, lipid inclusions and rare carbohydrate granules could be observed. However, some cells displayed an apparently intact plasma membrane in which even the bilayer structure could be discerned, although their mitochondrial membranes appeared to be rather deteriorated (Fig. 16).

\section{Influence of culture conditions}

The validity of the tetrazolium-based cell-proliferation assays in estimating parasite numbers was confirmed by the linear association observed between absorbance values and parasite concentrations (ranging from 50000 to 400000 stages well ${ }^{-1}$ ). The results corresponding to one of the WST-1 experiments are presented in Fig. 17. This association was assessed by reference to the coefficient of determination from linear regression $\left(\mathrm{R}^{2}=0.987\right.$, slope $[\mathrm{m}]=0.0508 ; y$-intercept $\left.[\mathrm{b}]=8.05 \times 10^{-7}\right)$. Absorbance values, however, were always low. Parasite proliferation could not be verified by measuring DNA synthesis with the BRDU immunoassay using the same range of parasite concentrations.

\section{Culture media and temperature}

In several preliminary experiments using XTT and WST-1 assays, absorbance values obtained in M199 were higher than in DME/F12 or HMEM cultures. These differences were statistically significant in some experiments using 100000 stages per well. When the cell proliferation assays were subsequently repeated after different times in culture, a clear decrease in the signal in all the media was observed after $12 \mathrm{~h}$ p.i. (Fig. 18). Absorbance values were higher at $20^{\circ} \mathrm{C}$ than at $15^{\circ} \mathrm{C}$ in both M199 and DME/F12 media, but these differences were not statistically significant.

Based on these results, M199 and $20^{\circ} \mathrm{C}$ were chosen as the most adequate conditions for the parasite maintenance and for further experiments. A threshold number of 50000 stages well $^{-1}$ was required for the application of the tetrazolium-based metabolic assays.

\section{Use of conditioned medium}

The use of conditioned medium did not affect parasite growth, as differences between conditioned and control medium (M199 alone) were not appreciable, and the number of viable cells progressively decreased with time in both cases (Fig. 19).

\section{Addition of sera}

Absorbance values obtained by the WST-1 cell proliferation assay were significantly higher in culture media containing sera than in the control medium (Fig. 20). The highest readings were obtained with $10 \%$ heat-inactivated turbot serum at $1 \mathrm{~h} \mathrm{p.i.} \mathrm{At} 18$ and $42 \mathrm{~h}$ p.i., the highest absorbance values were also obtained in the presence of TS, either alone (10 or 5\% $\mathrm{TS})$ or in combination with FBS (5\% FBS + 5\% TS). However, at $42 \mathrm{~h}$ p.i. all values had decreased below those obtained at $1 \mathrm{~h}$ p.i. 

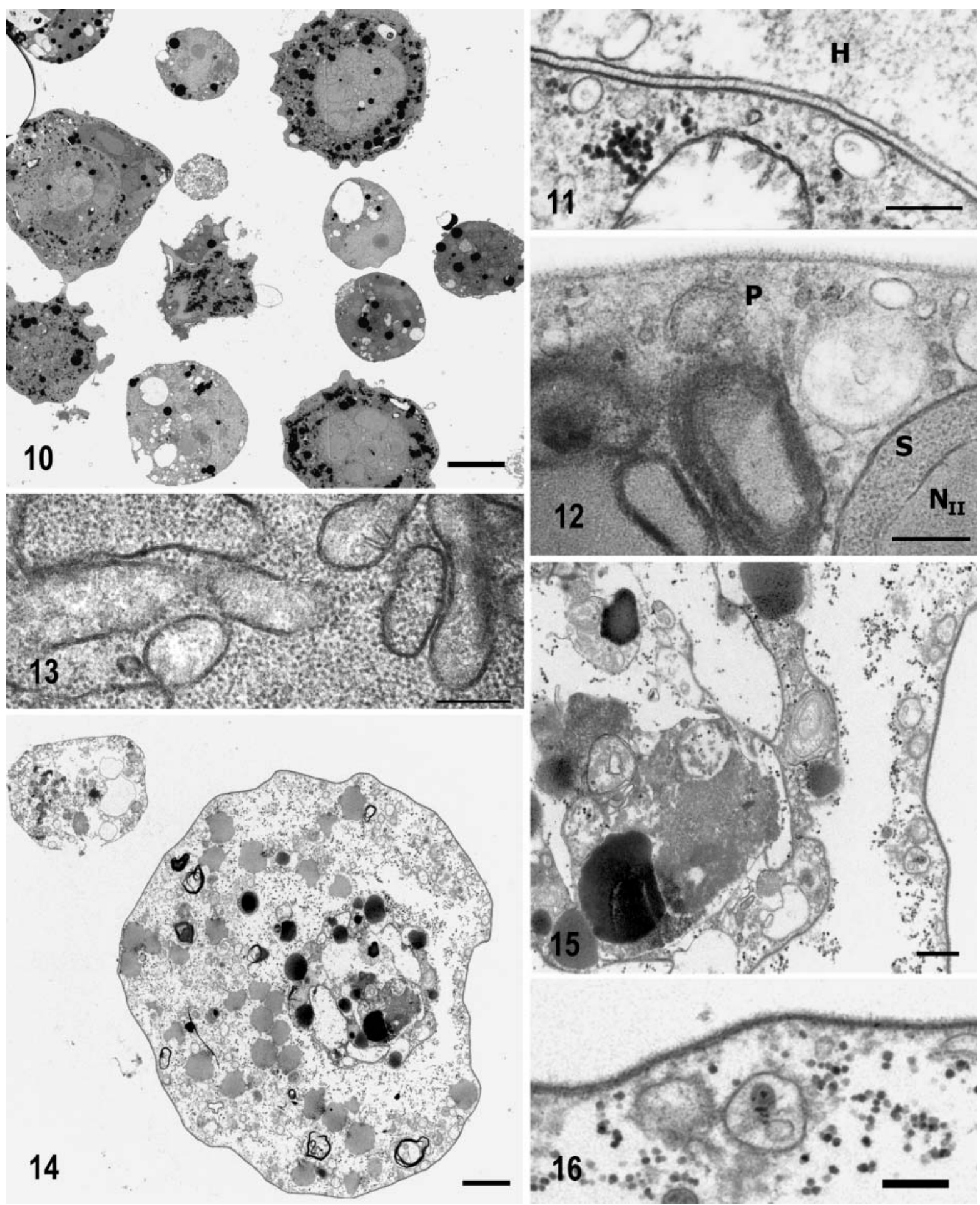

Figs. 10 to 16. Enteromyxum scophthalmi. Transmission electron microscope images. Figs. 10 to 13. Freshly obtained stages used for inoculation in culture; Fig. 10. Panoramic view of different normal stages; Fig. 11. Detail of junction between host (H) and parasite cell membranes; Fig. 12. Detail of normal stage showing secondary cell $(\overline{\mathrm{S}})$ with nucleus $\left(\mathrm{N}_{\mathrm{II}}\right)$, within a primary cell $(\mathrm{P})$, membrane of the primary cell is thickened, showing remnants of junction with a host cell; Fig. 13. Detail of parasite mitochondria in ri-

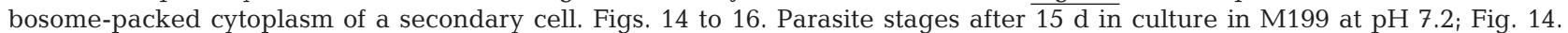
deteriorated stage with withered matrix and degenerated organelles in P and S cells; Fig. 15. Detail of lipid inclusions and degenerated cytoplasm and internal membranes with apparently intact plasma membrane (detail in Fig. 16). Scale bars $=5 \mu \mathrm{m}($ Fig. 10); 


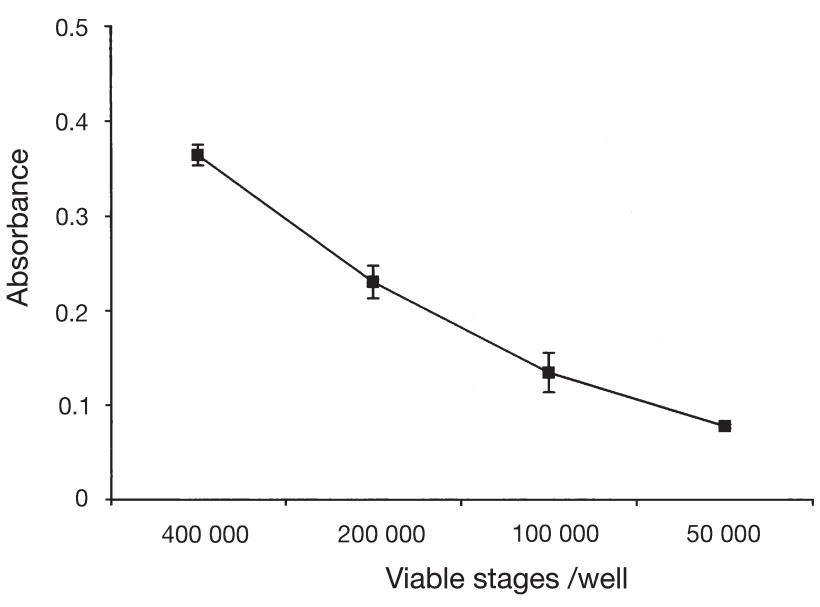

Fig. 17. Enteromyxum scophthalmi. Linear relationship between absorbance and number of parasite stages: WST-1 microplate cell-proliferation assay using freshly inoculated stages. Culture conditions $=$ medium $199, \mathrm{pH} 7.2,20^{\circ} \mathrm{C}$

\section{Effect of pH}

In some experiments using the WST-1 cell proliferation assay, higher absorbance values were obtained at $\mathrm{pH} 8.5$ than at $\mathrm{pH}$ 7.2. However, a stimulatory effected of high $\mathrm{pH}$ was not confirmed when the WST-1 assay and viable stage counts were used in parallel to study parasite growth at several points within a $48 \mathrm{~h}$ period (Fig. 21). According to viability counts, the number of viable stages was higher at $\mathrm{pH}$ 7.2 than at $\mathrm{pH} 8.5$ even in freshly inoculated parasites, and the difference was more noticeable and statistically significant after $24 \mathrm{~h}$ in culture. After $48 \mathrm{~h}$, viability at both pHs was very low, but still higher at $\mathrm{pH}$ 7.2. In contrast, the WST-1 assay gave higher readings after $24 \mathrm{~h}$ at $\mathrm{pH} 8.5$ than at $\mathrm{pH}$ 7.2. These differences did not hold after $48 \mathrm{~h}$, when WST-1 assay readings were similar at both pHs.

\section{Co-culture with TF cell line}

The maintenance of the parasite in the presence of turbot cells did not improve the yield of the cultures. The number of viable stages decreased by Day 1 p.i. in all the experiments, regardless of the number of stages inoculated (Fig. 22). Indeed, viability counts were significantly higher in the absence of TF-cells on Day 1 p.i., although these differences did not hold from Day 2 p.i. onwards. The decrease in the number of viable parasites with time was also verified in this experiment. It is also remarkable that the host cell line followed the inverse pattern, since the number of

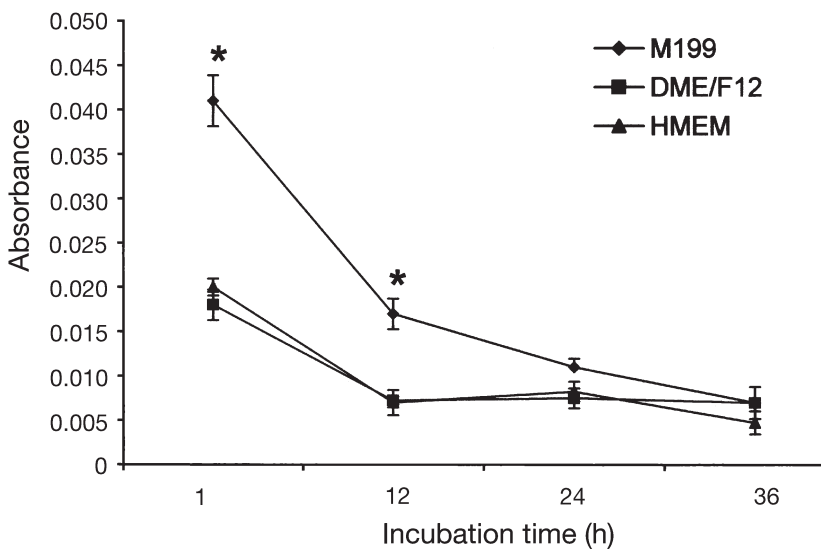

Fig. 18. Enteromyxum scophthalmi. Absorbance values obtained with WST-1 cell-proliferation assay on stages seeded in different culture media and assayed over $36 \mathrm{~h}$ period. Culture conditions $=100000$ stages seeded per well, $\mathrm{pH} 7.2$ and $20^{\circ} \mathrm{C}$. M199: Medium 199; DME/F12: Dulbecco's modified Eagle's medium/Ham's nutrient mixture F-12; HMEM: Eagle's minimum essential medium with Hank's salts

viable TF cells decreased during the first $2 \mathrm{~d}$ of the experiment but had recovered by Day 3. This situation is illustrated by the IM images of these cultures (Figs. 23 to 27). When TF cells were grown on Thermanox coverslips, and these were fixed and stained (Figs. 28 \& 29) parasite stages were observed on the surface of the monolayer on Day 1 p.i., some of them located intracellulary (Fig. 28). However, at later incubation times the number of intracellular stages decreased and all parasites degenerated.

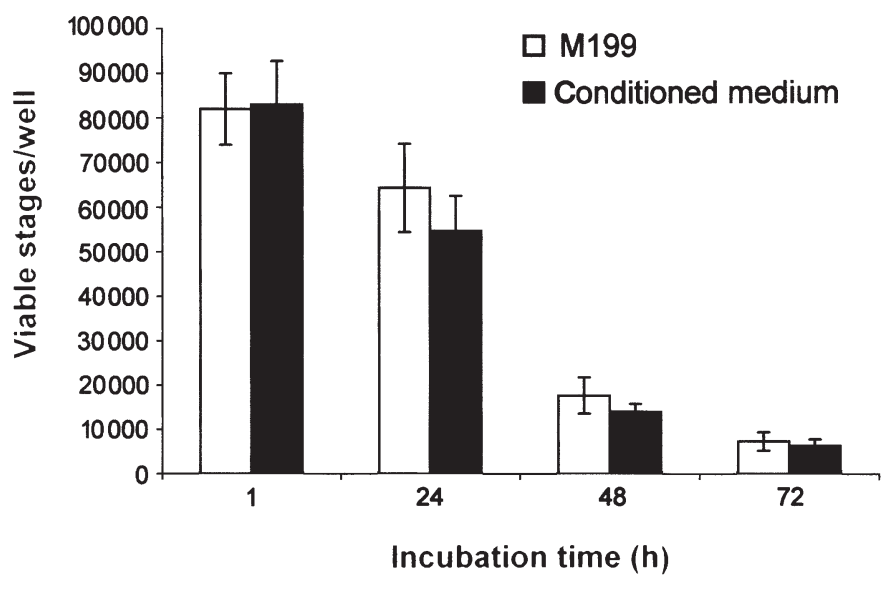

Fig. 19. Enteromyxum scophthalmi. Effect of conditioned medium in cultures. Viable parasites in wells were counted at different times using the eosin-exclusion method. Culture conditions $=100000$ stages seeded per well, $7.2 \mathrm{pH}$ and $20^{\circ} \mathrm{C}$ 


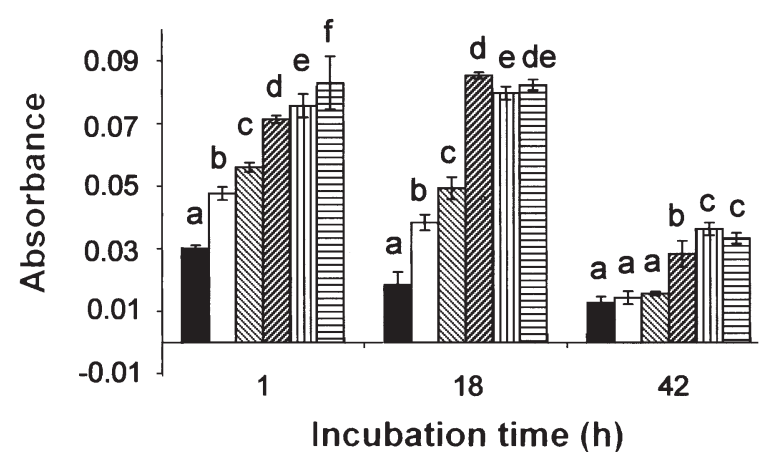

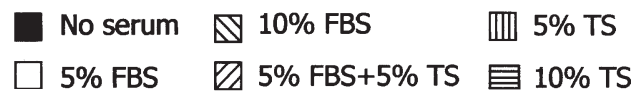

Fig. 20. Enteromyxum scophthalmi. Effect of serum supplementation on survival in vitro. Absorbance values obtained with WST-1 microplate cell-proliferation assay on stages seeded in media containing different types of sera. Culture conditions $=$ initial number of 50000 stages seeded per well, $\mathrm{pH} 7.2,20^{\circ} \mathrm{C}$. Different letters indicate statistically significant differences $(p<0.05)$ between conditions at each time point. FBS: $10 \%$ heat-inactivated bovine serum; TS: turbot serum

\section{DISCUSSION}

Preliminary assays and morphological studies demonstrated several changes in the parasite stages studied for some days after their inoculation in culture media. However, after an apparent proliferation until Days 7 and 9 p.i., evidenced by the abundance of young stages, no further development occurred, and only non-viable stages were detected by Day 15 p.i. Sporulation was not observed in any of the conditions

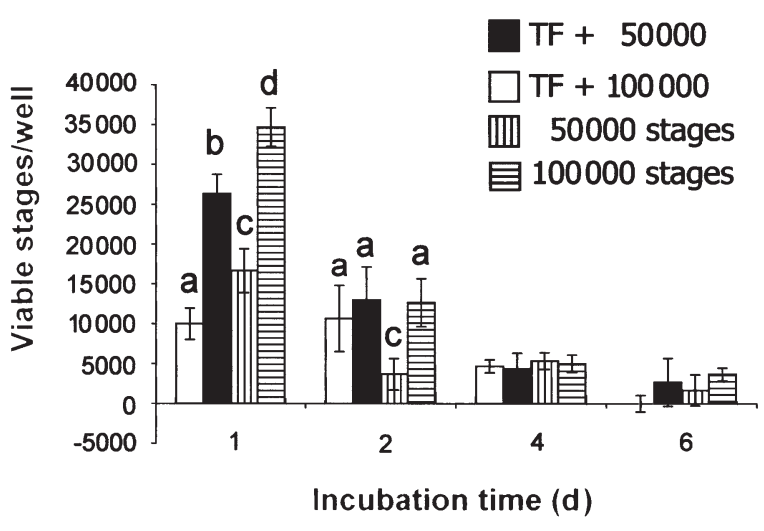

Fig. 22. Enteromyxum scophthalmi. Co-cultivation of parasite with turbot fin (TF) cell line. Dye-exclusion viability counts of parasites seeded at 2 concentrations with or without TF cells were carried out daily over $6 \mathrm{~d}$ period. Cultures were kept in Leibovitz's L-15 medium, pH 7.2 and $20^{\circ} \mathrm{C}$. Different letters indicate statistically significant differences $(\mathrm{p}<0.05)$ between conditions at each time point

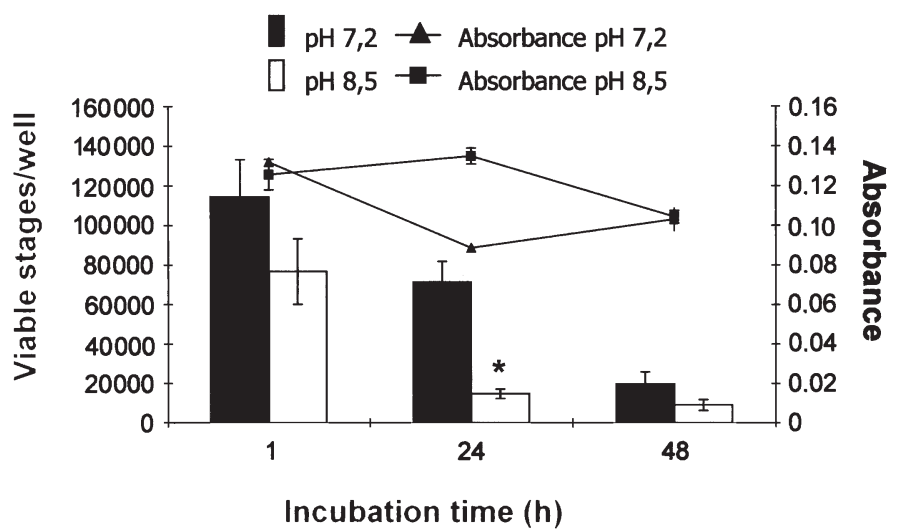

Fig. 21. Enteromyxum scophthalmi. Effect of $\mathrm{pH}$ on cultures, evaluated using both WST-1 microplate cell proliferation assay and dye-exclusion viability counts at different points over $48 \mathrm{~h}$ period. Culture conditions $=$ medium 199, initial number of 100000 stages well $^{-1}, 20^{\circ} \mathrm{C}$. Statistically significant differences $(p<0.05)$ between conditions at each time point

tested. This is in contrast with previous results obtained by Palenzuela et al. (1994) and Yokoyama \& Yutaka (1999), who succeeded in obtaining spores in vitro from early stages of Ceratomyxa spp. It must be noted, however, that Enteromyxum scophthalmi develops very low numbers of spores in its type host, and these are usually located within the intestinal epithelium and seldom in the lumen (Palenzuela et al. 2002, Redondo et al. 2002). This could in part explain the absence of massive in vitro sporulation of E. scophthalmi, such as that reported for the less fastidious, coelozoic Ceratomyxa species.

Apart from the morphological and viability studies, we used metabolic microplate assays to evaluate Enteromyxum scophthalmi's development in vitro. Using tetrazolium salts, a correlation was observed between absorbance values and the number of freshly inoculated parasites in culture. However, no proliferation with time could be demonstrated, and absorbance values decreased after some time in culture. In parasites maintained in media at different $\mathrm{pHs}$, the results of tetrazolium-based tests contradicted those of viability counts, as absorbance was higher at basic than at neutral $\mathrm{pH}$, whereas the viable cell counts displayed an opposite pattern. This could be due to the biochemical and cellular basis of these assays, since XTT and WST-1 can be efficiently reduced by NADH, NADPH, and other compounds in the presence of intermediate electron acceptors, even in the absence of cells and enzymes (Berridge et al. 1996). Furthermore, according to Berridge et al. (1996) WST-1 reduction seems to occur extracellularly or at the plasma membrane. Thus, the reducing environment of the basic media could 
facilitate non metabolic-associated reduction of the salt, resulting in a lack of correspondence of absorbance values and counts of viable stages.

The BRDU cell-proliferation assay also proved inadequate for studying Enteromyxum scophthalmi cultures. A very low signal was obtained in all cases, indicating that DNA synthesis is rare, and undetectable under the assay conditions.

In several experiments, viable stages were present up to $12 \mathrm{~d}$ p.i., but in all cases their number decreased with time, and the cultures could not be maintained alive even for a relatively short period. Attempts using different media, including conditioned medium, were also unsuccessful. Although the results obtained with M199 were somewhat better than with DME/F12 or HMEM, the decline in viable stages occurred as early as $12 \mathrm{~h}$ p.i. and was very evident by $24 \mathrm{~h}$ p.i.
Ultrastructural studies of cultured stages on Day 15 p.i. confirmed their degeneration. Most stages had lost the characteristic features of freshly inoculated stages, and the cytoplasmic contents and organelles were absent or withered. However, the apparent integrity of the plasma membrane of several stages was remarkable.

In view of the poor results obtained in the different media and conditions, attempts were made to grow the parasites in the presence of host cells using the TF line. Even here, the number of viable stages decreased with time, whereas the cell line (initially affected by the parasite) soon recovered. In the course of these experiments it was demonstrated that the parasites could penetrate into TF cells, although even then they did not undergo further development. An intracellular location of Enteromyxum scophthalmi in the intestinal
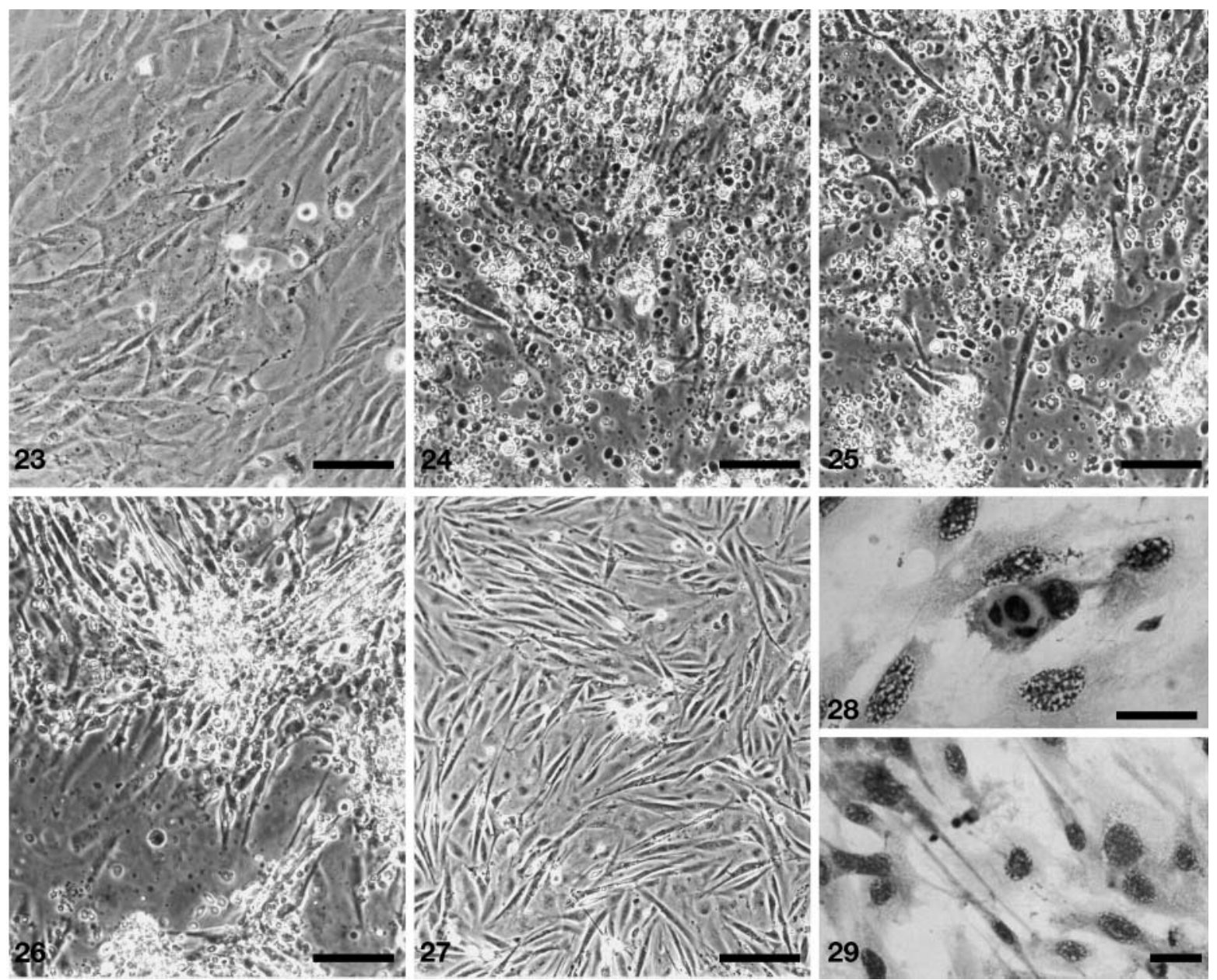

Figs. 23 to 29. Enteromyxum scophthalmi. Co-cultivation of parasite with turbot fin (TF) cell line. Figs. 23 to 27 . Cultures under inverted microscope, showing TF line before inoculation of the parasite (Fig. 23) and after seeding on Days 1 (Fig. 24 ), 3 (Fig. 25), 7 (Fig. 26) and 11 (Fig. 27); note complete recovery of TF monolayer and absence of parasite stages by Day 11 . Figs. 28 \& 29 . Toluidine blue-stained TF cells grown in Thermanox coverslips, showing intracellulary located stage in parasite-seeded monolayer (Fig. 28) and control TF cells (Fig. 29). Scale bars $=55 \mu \mathrm{m}$ (Figs. 23, 24, $25 \& 26$ ); $110 \mu \mathrm{m}$ (Fig. 27); and $10 \mu \mathrm{m}$ (Figs. 28 \& 29) 
epithelial cells of the fish host was demonstrated in previous ultrastructural studies, although most of the stages were located among epithelial cells (Palenzuela et al. 2002). In advanced infections, parasite stages are frequently released into the intestinal lumen enveloped by, or together with, epithelial debris. Although the parasites can remain viable in this location, damaged luminal stages are also frequent, indicating that this site may not be suitable for parasite development. However, the short-term survival of developmental stages in seawater as demonstrated in the current work could partially explain the direct, spontaneous fish-to-fish transmission of this parasite demonstrated in a previous study (Redondo et al. 2002). The short-term resistance of the parasite's developmental stages to significant osmotic shock upon release into seawater may be facilitated by some degree of protection from the mucosa remnants released with them, but is also possibly related to the resistance of the plasma membrane.

The need for alternatives to in vivo animal experimentation in parasitology has stimulated efforts to develop other techniques, such as in vitro cultivation of parasites (Eckert 1997). However, parasite cultivation is often a difficult task, and is largely influenced by the type of development and life cycle of the parasite in question. As a general rule, protozoan parasites with asexual, proliferative phases are easier to maintain or propagate in culture, at least during the early part of their developmental cycle. Intracellular protozoans such as Apicomplexa often require co-culture in cell lines (Tzipori 1998), and the complexity of the life histories of Metazoan parasites usually imposes limitations for in vitro cultivation approaches. Relatively few fish parasites can be cultured or maintained in vitro, and these are mainly protozoans: blood flagellates (Thomas \& Woo 1992, Bienek \& Belosevic 1997, Davies et al. 1999), intestinal diplomonad flagellates (Buchmann \& Uldal 1996, Sterud 1998, Sangmaneedet \& Smith 2000), ectoparasitic dinoflagellates (Oestmann \& Lewis 1996), histophagous ciliates (Crosbie \& Munday 1999) and microsporidians (Wongtavatchai et al. 1994).

Other than the sporulation of Ceratomyxa spp and Myxobolus sp., no myxozoan culture has been obtained to date. Despite considerable effort, Enteromyxum scophthalmi could not be maintained in culture even in the short term. It is evident that the requirements of this parasite are not fulfilled by such conditions. A heteroxenous life cycle involving an intermediate host has been demonstrated for several myxozoans (Kent et al. 2001) although not as yet for $E$. scophthalmi. This complex life cycle adds difficulties to the in vitro culture of myxozoans. However, it should be possible to maintain the proliferative phase of E. scophthalmi, which occurs in the intestinal tissues, mainly intercellularly, but in close conjunction with epithelial cells (Palenzuela et al. 2002, Redondo et al. 2003). Its inability to proliferate in culture could be related to a strict dependence on host intestinal tissues and the high pathogenicity of this parasite.

The use of conditioned media or the presence of a host cell line did not improve the situation. Nevertheless, some parasites can be propagated or better culture yields can be achieved using these strategies. Thus, the development of some fish ectoparasites such as Amyloodinium ocellatum depends on the presence of a gill cell line (Noga 1989), while Ichthyophthirius multifiliis yields clearly improved in the presence of the epithelioma papulosum cyprini cell line as substrate (Nielsen \& Buchmann 2000). Continuous in vitro propagation of the asexual sporocyst of Schistosoma mansoni relies critically on the presence of Bge cells or, alternatively, on the use of conditioned medium and reduced oxygen levels, to compensate for the high sensitivity of this parasite to oxidative damage (Ivanchenko et al. 1999).

In the case of myxozoans, little is known about their biochemistry and metabolic pathways apart from the presence of reserves (glycogen and lipid droplets) and certain carbohydrate terminals in some development stages. Uspenskaya (1982) distinguished myxozoan species with aerobic and anaerobic types of metabolism, and related the presence of high amounts of glycogen and neutral fat to more anaerobic preferences. However, this same author reported the existence of both aerobic and anaerobic types of metabolism in different myxozoan species and, furthermore, in life cycle stages of a single species, concluding that these organisms are neither obligate aerobes nor anaerobes. Similar situations have been described for other protozoan and metazoan parasites, and are well illustrated by the examples of Trypanosoma brucei or Ascaris suum. Interestingly, the aerobic-anaerobic transitions in these species are reflected by changes in the numbers of mitochondrial cristae and enzymatic systems in their stages (Vickerman et al. 1991, Kita et al. 1997).

The rich culture media used in our experiments should have covered the main nutritional requirements of Enteromyxum scophthalmi, even though they did not support its proliferation. Therefore, the key factors for the survival and propagation of this parasite are probably related to some enzymatic routes or growth factors, and are difficult to ascertain at the present state of knowledge. Mitochondrial pathways might play an important role in the onset of the cultures; mitochondria are key organelles controlling control cell death, and alterations leading to cellular degeneration are frequently linked to mitochondrial damage. In cultured E. scophthalmi, ultrastructural damage of 
mitochondria was ascertained, and the metabolic assays demonstrated low and decreasing levels of mitochondrial activity. However, the mechanisms involved are unknown. Our results stress the need for studies on myxosporean metabolic and biochemical pathways, although these are hardly realizable without a continuous and reliable source of material. In the case of E. scophthalmi, the existence of direct fish-tofish transmission provides an experimental model of 'in vivo' maintenance of the parasite. Future attempts at its cultivation will be focus on the use of intestinal explants to study the parasite/host interaction and the mechanisms involved.

Acknowledgements. This study was financed by the EU and Spanish Government through the research grant FEDER 1FD97-0679-C02-01. Additional support was provided by Stolt Sea Farm, S.A. The authors are thankful to the Electron Microscopy Services from the Universities of Barcelona and Valencia.

\section{LITERATURE CITED}

Berridge MV, Tan AS, McCoy KD, Wang R (1996) The biochemical and cellular basis of cell proliferation assays that use tetrazolium salts. Biochemica 4:14-19

Bienek DR, Belosevic M (1997) Comparative assessment of growth of Trypanosoma danilewskyi (Laveran \& Mesnil) in medium containing fish and mammalian serum. J Fish Dis 20:217-221

Branson E, Riaza A, Alvarez-Pellitero P (1999) Myxosporean infection causing intestinal disease in farmed turbot, Scophthalmus maximus (L.) (Telostei: Scophthalmidae). J Fish Dis 22:395-400

Buchmann K, Uldal A (1996) Temperature, pH and bile dependent in vitro cultivation of Hexamita salmonis from rainbow trout Oncorhynchus mykiss intestine. Dis Aquat Org 24:169-172

Crosbie PBB, Munday BL (1999) Enviromental factors and chemical agents affecting the growth of the pathogenic marine ciliate Uronema nigricans. Dis Aquat Org 36:213-219

Davies AJ, Thorborn DE, Mastri C, Daszak P (1999) Ultrastructure of culture forms of the eel trypanosome, Trypanosoma granulosum Laveran \& Mesnill, 1902, exposed to polyamine biosynthesis inhibitors. J Fish Dis 22: $285-298$

Diamant A (1997) Fish-to-fish transmission of a marine myxosporean. Dis Aquat Org 30:99-105

Eckert J (1997) Alternatives to animal experimentation in parasitology. Vet Parasitol 71:99-120

Hallet SL, O'Donoghue PJ, Lester RJG (1998) Structure and development of a marine actinosporean, Sphaeractonomyxon ersein n. sp. (Myxozoa). J Eukaryot Microbiol 4: $142-150$

Hedrick RP, Macconnell E, De Kinkelin P (1993) Proliferative kidney disease of salmonid fish. Annu Rev Fish Dis 3:277-290

Hoffman GL Y, Hoffman GL (1972) Studies on the control of whirling disease (Myxosoma cerebralis). I. The effects of chemicals on spores in vitro, and of calcium oxide as a disinfectant in simulated ponds. J Wildl Dis 8:49-53

Ibarra AM, Gall GAE, Hedrick RP (1991) Susceptibility of two strains of rainbow trout Oncorhynchus mykiss to experimentally induced infections with the myxosporean Ceratomyxa shasta. Dis Aquat Org 10:191-194

Ikeda J (1912) Studies on some sporozoan parasites of sipunculoids. I. The life history of a new actinominomyxidian, Tetractinomyxum intermedium g. et sp. nov. Arch Protistenkd 25:240-242

Ivanchenko MG, Lerner JP, McCormick RS, Toumadje A and 6 others (1999) Continuous in vitro propagation and differentiation of cultures of the intramolluscan stages of the human parasite Schistosoma mansoni. Proc Natl Acad Sci USA 96:4965-4970

Kent ML, Andree KB, Bartholomew JL, El-Matbouli M and 12 others (2001) Recent advances in our knowledge of the Myxozoa. J Eukaryot Microbiol 48:395-413

Kita K, Hirawake H, Takamiya S (1997) Cytochromes in the respiratory chain of helminth mitochondria. Int J Parasitol $27: 617-630$

Køie M (2000) First record of an actinosporean (Myxozoa) in a marine polychaete annelid. J Parasitol 86:871-872

Moran JDW, Whitaker DJ, Kent ML (1999) Natural and laboratory transmission of the marine myxozoan parasite Kudoa thyrsites to Atlantic salmon. J Aquat Anim Health 11:110-115

Nielsen CV, Buchmann K (2000) Prolonged in vitro cultivation of Ichthyophthirius multifiliis using an EPC cell line as substrate. Dis Aquat Org 42:215-219

Noga EJ (1989) Culture conditions affecting the in vitro propagation of Amyloodinium ocellatum. Dis Aquat Org 6: $137-143$

Oestmann DJ, Lewis DH (1996) Improved cell culture propagation of Amyloodinium ocellatum. Dis Aquat Org 24: $173-178$

Palenzuela O, Sitjà-Bobadilla A, Alvarez-Pellitero P (1994) In vitro sporulation of Ceratomyxa sp. (Myxosporea: Bivalvulida) from Sparus aurata L. (Teleostei: Sparidae). Icopa VIII. Abstracts Book (Vol 1). Turkish Society for Parasitology, Izmir, p 195

Palenzuela O, Redondo MJ, Alvarez-Pellitero P (2002) Description of Enteromyxum scophthalmi gen. nov, sp. nov. (Myxozoa), an intestinal parasite of turbot (Scophthalmus maximus L.) using morphological and ribosomal RNA sequence data. Parasitology 124:369-379

Redondo MJ, Palenzuela O, Riaza A, Macías A, Alvarez-Pellitero P (2002) Experimental transmission of Enteromyxum scophthalmi (Myxozoa), a parasite of turbot (Scophthalmus maximus). J Parasitol 88:482-488

Redondo MJ, Quiroga MI, Palenzuela O, Nieto JM, AlvarezPellitero P (2003) Ultrastructural studies on the development of Enteromyxum scophthalmi (Myxozoa), an enteric parasite of turbot (Scophthalmus maximus L.). Parasitol Res 90:192-202

Rhee JK (1994) Supplemental knowledge on survival of Thelohanellus kitauei spores in vitro. Korean J Parasitol 32:57-59

Rhee JK, Kim JO, Park BK (1990) Prophylactic and therapeutic studies on intestinal giant-cystic disease of the Israel carp caused by Thelohanellus kitauei. II. Effects of physical and chemical factors on $T$. kitauei spores in vitro. Korean J Parasitol 28:241-252

Sangmaneedet S, Smith SA (2000) In vitro studies on optimal requirements for the growth of Spironucleus vortens, an intestinal parasite of the freshwater angelfish. Dis Aquat Org 39:135-141

Siau Y (1977) Premiers stades du développement expérimental, en cultures, de spores de la Myxosporidie Myxobolus exiguus Thélohan, 1895. Z Parasitenkd 62:1-6 
Spurr AR (1969) A low-viscosity epoxy-resin embedding medium for electron microscopy. J Ultrastruct Res 26: 31-43

Sterud E (1998) In vitro cultivation and temperature-dependent growth of two strains of Spironucleus barkhanus (Diplomonadida: Hexamitidae) from Atlantic salmon Salmo salar and grayling Thymallus thymallus. Dis Aquat Org 33:57-61

Thomas PT, Woo PTK (1992) In vitro culture and multiplication of Cryptobia catostomi and experimental infection of white sucker (Catostomus commersoni). Can J Zool 70: 201-204

Tzipori S (1998) Cryptosporidiosis: laboratory investigations and chemotherapy. In: S Tzipori (ed) Advances in parasitology, Vol 40: Opportunistic protozoa in humans. Academic Press, New York, p 188-221

Uspenskaya AV (1982) New data on the life cycle and biology of Myxosporidia. Arch Protistenkd 126:309-338

Vickerman K, Brugerolle G, Mignot JP (1991) Mastigophora

Editorial responsibility: Wolfgang Körting,

Hannover, Germany
In: Harrison FW, Corliss JV (eds) Microscopic anatomy of invertebrates, Vol 1. Protozoa. Wiley-Liss, New York, p 13-159

Wolf K, Markiw ME (1976) Myxosoma cerebralis: in vitro sporulation of the myxosporidan of salmonid whirling disease. J Protozool 23:425-427

Wongtavatchai J, Conrad PA, Hedrick RP (1994) In vitro cultivation of the microsporidian Enterocytozoon salmonis using newly developed medium for salmonid lymphocytes. J Tissue Cult Methods 16:125-131

Yokoyama H, Yutaka F (1999) In vitro sporulation of Myxobolus spirosulcatus and Ceratomyxa spp. (Myxozoa: Myxosporea) infecting the gallbladder of yellowtail Seriola quinqueradiata. In: European Association of Fish Pathologists-EAFP (ed) Ninth international conference 'Diseases of Fish and Shellfish', Rhodes, p 210 (Abstract)

Yokoyama H, Ogawa K, Wakabayashi H (1995) Chemoresponse of actinosporean spores of Myxobolus cultus to skin mucus of goldfish Carassius auratus. Dis Aquat Org 21:7-11

Submitted: August 20, 2002; Accepted: January 3, 2003 Proofs received from author(s): June 11, 2003 